\title{
Effect of doping on TSD relaxation in cellulose acetate films
}

\author{
P K KHARE*, P L JAIN ${ }^{\dagger}$ and R K PANDEY ${ }^{*}$ \\ Department of Postgraduate Studies and Research in Physics and Electronics, Rani Durgavati University, \\ Jabalpur 482 001, India \\ ${ }^{\dagger}$ Government Postgraduate College, Damoh 470 661, India \\ ${ }^{\ddagger}$ Department of Physics, Dr H.S. Gour University, Sagar 470 002, India
}

MS received 5 October 1999; revised 19 September 2000

\begin{abstract}
Thermally stimulated depolarization current (TSDC) studies have been performed on solution grown cellulose acetate films doped with different concentrations of acrylic acid (AA) prepared at the poling temperatures $\left(40-75^{\circ} \mathrm{C}\right)$ with poling fields $(10-50 \mathrm{kV} / \mathrm{cm})$. The TSDC spectra of pure and AA doped CA films reveal two relaxation peaks at $80^{\circ} \mathrm{C}$ and $180 \pm 2^{\circ} \mathrm{C}$, having activation energies centred around 0.25 and $0.55 \mathrm{eV}$. The phenomena of the existence of these current maxima have been analyzed and discussed in terms of the molecular motion of the polar side groups and release of the remaining part of the frozen dipoles by their cooperative motion with adjoining segments of the main polymer chain. The peak currents, released charge and activation energies associated with the peaks are affected by AA doping. The effect of doping with acrylic acid on the discharge current indicates the formation of molecular aggregates.
\end{abstract}

Keywords. TSD relaxation; cellulose acetate; acrylic acid; molecular aggregates.

\section{Introduction}

The thermally stimulated depolarization current (TSDC) is a method for investigating the electrical properties of high resistivity solids via the study of thermal relaxation effects and as such offers an alternative scheme to the conventional bridge methods or current-voltage temperature measurements. Since TSDC is governed by relaxation phenomena specific to the polymers, it can be used to study molecular motions in them at low frequency. The TSDC is an effective tool for extracting information about internal structure and molecular relaxations, as well as the establishment and decay of space charge due to trapping of charge carriers and their subsequent thermal release from traps in a polymer (Turnhout 1975; Sessler 1980; Khare and Singh 1994; Khare and Chandok 1995a, b). It has been shown that the total charge stored in a polymer electret and the different mechanisms which contribute to this charge are sensitive to the structure of the forming material. Charge storage may be due to either dipolar orientation or space charge. The space charges cause the electret to be not locally neutral. In addition to the excess charges, there must be free equilibrium charges in the electret which are responsible for its intrinsic ohmic conductivity. The reorientation of aligned dipoles at random due to the thermal agitation, the motion of excess charges originating from space charge limited drift and diffusion

\footnotetext{
*Author for correspondence
}

and ohmic conduction result in the decay of the net charge of an electret during TSC. The local ohmic conduction currents arise from the movement of the equilibrium charges by the local electric field. It neutralizes a part of the excess charges by supplying opposite equilibrium charges. The relaxation times of all the decay process depend exponentially on temperature so the decay processes are accelerated during TSC. Cellulosic materials are excellent electrical insulators. When dry, they contain a large number of traps and exhibit structural deformations at certain transition temperature (Danno et al 1983; Upadhyay et al 1998). The cellulosic derivatives C-O-C groups are built into the main polymer chain linearly and also in the form of a 6-membered gluco-pyranose ring with flexible polar side groups. The cellulose molecule is ribbon-like in form, more explicitly is a sequence of the flat plates (the rings of atoms) linked together (by the oxygen bridges). At the oxygen bridge, bending out of the plane of the ribbon and twisting are fairly easy so that the molecule is quite flexible although much stiffer than a polyethylene chain. The hydroxyl $(-\mathrm{OH})$ groups strongly attract other hydroxyl groups through the formation of hydrogen bonds. The TSDC in pure cellulose acetate has been reported (Verma and Bhatnagar 1976; Upadhyay et al 1999), but no such measurements have been made in acrylic acid doped cellulose acetate (CA). An efficient control over electrical properties of polymers is achieved by doping the polymer with suitable dopant. Acrylic acid was selected as a doping substance for two reasons. First it is a monomer, i.e. polymer making substance and hence 
its chances of making changes in the properties of CA seem to be more. Second it is $\alpha-\beta$ unsaturated carbonyl compound which contains both carbon-carbon double bond and carbon-oxygen double bond and hence the chances of linking with the CE chains are increased.

\section{Experimental}

The isothermal immersion technique was applied for preparing thin films of pure and acrylic acid (AA) doped cellulose acetate (CA). The solution was prepared in a glass beaker by first dissolving $2 \cdot 1 \mathrm{~g} \mathrm{CA}$ in $30 \mathrm{ml}$ chemically pure chloroform at room temperature and continuously stirred for $30 \mathrm{~min}$ by means of a teflon-coated magnetic stirrer. Thereafter, it was stirred and heated to $40^{\circ} \mathrm{C}$ to yield a homogeneous solution. The solution was then immersed in a constant temperature oil bath. Ultrasonically cleaned vacuum metallized microscopic glass slides were immersed vertically into the solution for a period of about $10 \mathrm{~min}$. After the deposition of the film the glass slide was taken out and dried in an oven at $40^{\circ} \mathrm{C}$ for $24 \mathrm{~h}$. This was followed by room temperature outgassing at $10^{-5}$ torr for a further period of $24 \mathrm{~h}$. The upper electrode was also vacuum deposited on the upper surface of the film to obtain a sandwich configuration. The doped CA films were also prepared by the same technique under the identical conditions of taking $2 \cdot 1 \mathrm{~g}$ of $\mathrm{CA}$ into well stirred $1 \mathrm{ml}$ of AA thoroughly mixed with $30 \mathrm{ml}$ of chloroform. The doping concentration was changed by varying the amount of AA to be added in the solvent such that the total volume of solvent and AA remains constant. Two types of doped samples were prepared viz. (i) samples doped with lower concentration (1 $\mathrm{ml}$ of AA in $30 \mathrm{ml}$ of chloroform), and (ii) higher concentration (6 $\mathrm{ml}$ of AA in $25 \mathrm{ml}$ of chloroform).

The voltage was applied from a high voltage unit EC$4800 \mathrm{D}$ and current was recorded with an electrometer (Keithley 600B) which was carefully shielded and grounded to avoid ground loops or extraneous electrical noise. A linear heating rate of $4^{\circ} \mathrm{C} / \mathrm{min}$ was used. The thickness of the sample was of the order of $20 \mu \mathrm{m}$ which was estimated by measuring the capacitance of the fabricated sandwiches (Khare and Srivastava 1992, 1993).

In the present case, pure and acrylic acid doped CA thermoelectrets were formed by a thermal method under polarizing conditions of temperature $\left(40-75^{\circ} \mathrm{C}\right)$ and fields $(10-50 \mathrm{kV} / \mathrm{cm})$. The method of polarization of sample and measurement of TSC was the same as reported earlier (Khare and Srivastava 1992, 1993).

The depolarization kinetic data, i.e. activation energy, charge released and relaxation times for the observed peaks of pure and acrylic acid doped CA have been calculated using initial rise method of Garlick and Gibson (1973), Simmon's rule and Bucci et al (1966) theory, respectively (table 1).

\section{Results and discussion}

Figure 1 shows the thermally stimulated depolarization current (TSDC) characteristics of pure and acrylic acid (AA) doped cellulose acetate (CA) polarized at $50^{\circ} \mathrm{C}$ with different polarizing fields $\left(E_{\mathrm{p}} \mathrm{s}\right)$ (i.e. 10,25 and $50 \mathrm{kV} / \mathrm{cm}$ ) using a heating rate of $4^{\circ} \mathrm{C} / \mathrm{min}$. It is seen from the curves of figure 1 that two peaks, viz. I and II, appear in each characteristic in the ascending order of temperature. The first peak is observed to be centred around $80^{\circ} \mathrm{C}$ and the second peak around $182 \pm 2{ }^{\circ} \mathrm{C}$. With the increase in $E_{\mathrm{p}}$, the position $\left(T_{\mathrm{m}}\right)$ of both the peaks remains unchanged more or less, whereas the magnitude of the peak current increases. Figure 1 also shows TSDC spectrum for AA doped (lower and higher concentration) CA films. Doping of CA with lower and higher concentrations causes the peak current to increase in magnitude. Activation energy values centred around $0.26 \mathrm{eV}$ for peak I and $0.55 \mathrm{eV}$ for peak II, respectively. The value of activation energy from the full curve method comes out to be 0.25 and $0.56 \mathrm{eV}$

Table 1. Depolarization kinetic data for the observed peaks of pure and acrylic acid doped cellulose acetate films at poling temperature $T_{\mathrm{p}}=50^{\circ} \mathrm{C}$ with various poling fields.

\begin{tabular}{|c|c|c|c|c|c|c|}
\hline \multirow[b]{2}{*}{ Sample } & \multirow[b]{2}{*}{$\begin{array}{c}\text { Field } \\
(\mathrm{kV} / \mathrm{cm})\end{array}$} & \multicolumn{2}{|c|}{$\begin{array}{l}\text { Activation } \\
\text { energy }(\mathrm{eV})\end{array}$} & \multirow{2}{*}{$\begin{array}{l}\text { Peak current } \\
\qquad \begin{array}{l}\text { (A) } \\
\ldots \times 10^{-11}\end{array}\end{array}$} & \multirow[b]{2}{*}{$\begin{array}{l}\text { Charge released } \\
\text { (Coul) }\end{array}$} & \multirow[b]{2}{*}{$\begin{array}{l}\text { Relaxation time } \\
\qquad(\mathrm{sec})\end{array}$} \\
\hline & & $\begin{array}{l}\text { Peak } \\
\text { I }\end{array}$ & $\begin{array}{l}\text { Peak } \\
\text { II }\end{array}$ & & & \\
\hline $\begin{array}{l}\text { Pure cellulose } \\
\text { acetate }\end{array}$ & $\begin{array}{l}10 \\
25 \\
50\end{array}$ & $\begin{array}{l}0 \cdot 28 \\
0 \cdot 26 \\
0 \cdot 24\end{array}$ & $\begin{array}{l}0.59 \\
0.57 \\
0.56\end{array}$ & $\begin{array}{l}2 \cdot 0 \\
2 \cdot 7 \\
5 \cdot 8\end{array}$ & $\begin{array}{l}2.6 \times 10^{-9} \\
6 \cdot 0 \times 10^{-9} \\
9 \cdot 0 \times 10^{-9}\end{array}$ & $\begin{array}{l}8.8 \times 10^{4} \\
7 \cdot 3 \times 10^{7} \\
6 \cdot 5 \times 10^{9}\end{array}$ \\
\hline $\begin{array}{l}\text { Lower conc. of AA } \\
\text { doped CA }\end{array}$ & $\begin{array}{l}10 \\
25 \\
50\end{array}$ & $\begin{array}{l}0 \cdot 27 \\
0 \cdot 26 \\
0 \cdot 23\end{array}$ & $\begin{array}{l}0.47 \\
0.49 \\
0.41\end{array}$ & $\begin{array}{l}2 \cdot 4 \\
3 \cdot 4 \\
6 \cdot 0\end{array}$ & $\begin{array}{l}3 \cdot 5 \times 10^{-9} \\
5 \cdot 0 \times 10^{-9} \\
6 \cdot 8 \times 10^{-9}\end{array}$ & $\begin{array}{l}9.9 \times 10^{4} \\
8.4 \times 10^{6} \\
7.6 \times 10^{8}\end{array}$ \\
\hline $\begin{array}{l}\text { Higher conc. of AA } \\
\text { doped CA }\end{array}$ & 25 & 0.24 & 0.45 & $8 \cdot 0$ & $9.4 \times 10^{-8}$ & $5.5 \times 10^{9}$ \\
\hline
\end{tabular}


for first and second peaks, respectively which is in fair agreement with the value calculated from initial rise method.

Charge released $(Q)$ during the discharge was calculated by integrating the current versus temperature/time curves. Peak current versus field and charge released versus field plots for undoped and AA doped CA are shown in figure 2. Peak current and charge released for first peak show a linear rise with field. For undoped and AA doped CA samples, the behaviour of peak current and charge released for second peak is, however, different. Both peak current and charge released show non-linear variation with $E_{\mathrm{p}}$ in lower field region and they appear to be varying superlinearly with $E_{\mathrm{p}}$ in higher field region.

The value of activation energy associated with the first peak may correspond to molecular motion of the side group. A decrease in activation energy from 0.28 to $0.24 \mathrm{eV}$ is observed with the increase in polarizing field for pure and doped CA. This suggests that the peak is not due to discrete level having a single relaxation, but is a complex one having distributed activation energies. The peak current versus field and charge released vs field plots (figure 2) associated with peak suggests that the peak is of dipolar nature and the phenomenon may be attributed to the relaxation of the polar acetate groups, i.e. side chains from polarized state to one of equilibrium (Upadhyay et al 1999). The superlinear behaviour of peak current versus poling field plot for second peak in the higher field region indicates the space charge phenomenon. The second peak is not only due to single relaxation but seems to be more complex and may arise due to the release of the remaining part of the frozen dipoles by their cooperative

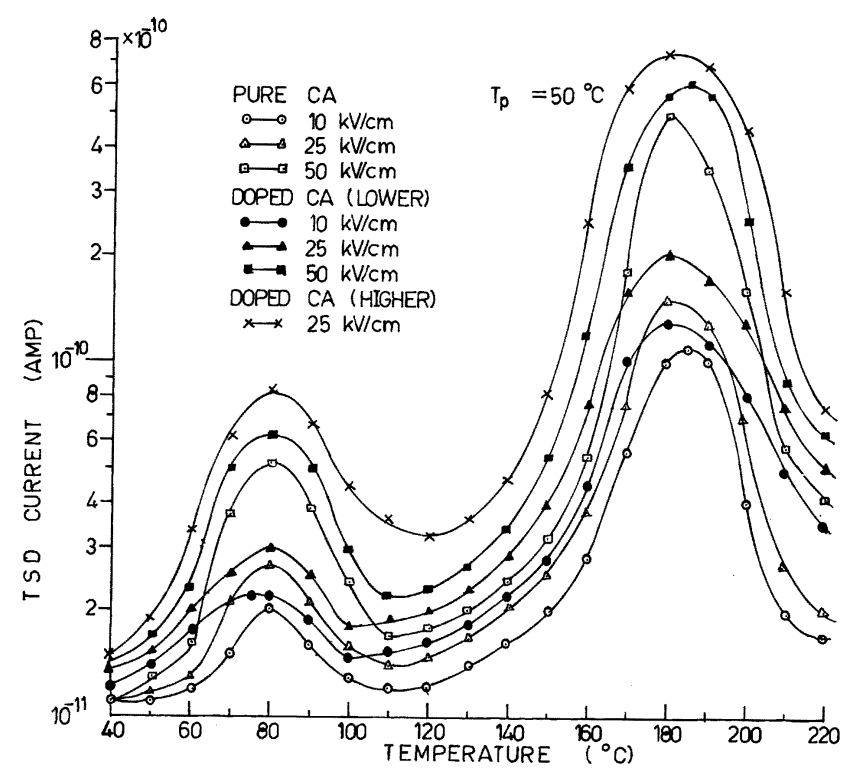

Figure 1. Thermally stimulated depolarization current thermograms for cellulose acetate doped with different concentrations of acrylic acid at constant polarizing temperature $\left(T_{\mathrm{p}}=50^{\circ} \mathrm{C}\right)$ with various polarization fields. motion with adjoining segments of the main polymer chains. The superlinear increase of peak current and release charge versus poling field in the higher field region suggests that the second peak is contributed both by electronic and ionic processes, arising in the bulk and injected from the electrodes which are subjected to a higher field. It is not a simple process but a complicated one of Maxwell-Wagner type (Pillai et al 1981).

Since the first peak ( $\beta$-relaxation) has been associated with the relaxation process arising from the thermal randomization of aligned dipoles of the acetate groups and the second peak arising due to release of remaining part of the frozen-dipoles by their cooperative motion with adjoining segments of the main polymer chain, it would be interesting to know how these are affected by the dopant. The dopant acrylic acid has the structural formula<smiles>C=CC(=O)O</smiles>

It is an $\alpha-\beta$ unsaturated carbonyl compound. It possesses both $\mathrm{C}=\mathrm{C}$ and $\mathrm{C}=\mathrm{O}$ double bond and exhibits the properties of these two functional groups (Talwar et al 1984). Once the temperature is raised the characteristic of the $\mathrm{C}=\mathrm{O}$ bond, acting as an electronegative acceptor, increases and the overall behaviour of the acrylic acid molecules is as a more electronegative acceptor collecting most of the electrons (or ions or both).

The concentration dependence of TSD current from polarized films, the appearance of the space charge polarization and its dependence on the dopant concentration suggest that the conductivity of $\mathrm{CA}$ is increased by doping of the matrix with acrylic acid. This increase is mainly due to the increase in carrier mobility. From the strong concentration dependence of the carrier mobility (Tiwari et al 1982; Khare and Chandok 1995a, b), it can

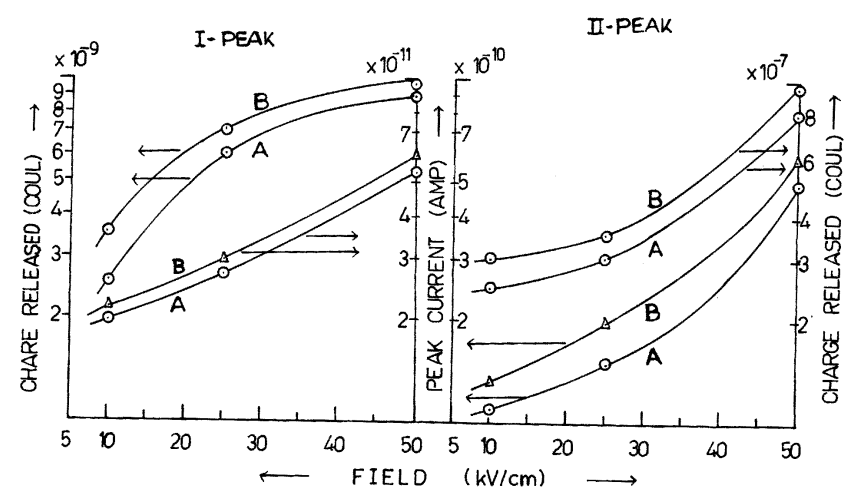

Figure 2. Charge released and peak current vs field plots for pure and acrylic acid doped cellulose acetate. Curves A and B correspond to pure and acrylic acid doped (lower concentration) cellulose acetates, respectively. 
be inferred that transport in molecularly doped systems occurs by a hopping process between sites associated with the dopant molecule. Following Pfister (1977), charge transport in molecularly dispersed systems can be visualized as the transition of an electron from a neutral molecule to a neighbouring molecular cation (hole transport) or from a molecular anion to a neighbouring neutral molecule (electron transport).

Acrylic acid, when doped in polymer, may reside at various sites. It may be substituted into the polymer chains, diffuse into the amorphous polymer forming charge transfer complexes (CTCs), or it may exist in the form of molecular aggregates between the polymer chains. In the case of CA, the possibility of acrylic acid substituting into the structure is negligible because of the lower electronegativity of AA compared with that of the carbonyl groups $(>\mathrm{C}=\mathrm{O})$ present in the acetyl groups of $\mathrm{CA}$. The formation of CTCs is considered to reduce the barrier between trapping sites, providing a conducting path through the polymer matrix. Such a phenomenon is assumed to decrease the activation energy of carriers and increase their mobility during polarization. In such a case a considerable amount of charge passes through the bulk of the sample and the current should be significantly less than that observed in undoped samples. In the present case, the current in the doped samples is greater than that observed in undoped samples. Such observations go against the possibility of CTC formation. Thus, the observed results suggest that AA forms molecular aggregates which may impede the motion of charge carriers and increase the barrier for transport of carriers during polarization. Then a greater amount of charge is assumed to be trapped in the process of polarization, and thus the magnitude of current may increase as is observed. Further, the optical absorption studies of pure and AA doped CA films (results not shown) do not show any appearance of charge transfer complex absorption band.
The positions and magnitudes of both the peaks in AA doped CA are nearly identical to their counterparts for pure $\mathrm{CA}$; this suggests that concentrations of dopant does not have any appreciable effect in modifying the characteristic properties of CA. The effect of doping is only to make the movement of segments somewhat easier.

\section{References}

Bucci C, Fieschi R and Guidi G 1966 Phys. Rev. 148574

Danno T, Miyasaka K and Ishikawa K 1983 J. Polym. Sci. Polym. Phys. 211527

Garlick G F J and Gibson A F 1973 Proc. Phys. Soc. 60128

Khare P K and Srivastava A P 1992 Indian J. Pure \& Appl. Phys. 30102

Khare P K and Srivastava A P 1993 Indian J. Pure \& Appl. Phys. 31126

Khare P K and Ranjeet Singh 1994 Polym. Int. 34407

Khare P K and Chandok R S 1995a Polym. Int. 38153

Khare P K and Chandok R S 1995b Phys. Status Solidi 147 509

Pfister G, Grammatica G and Mort J 1977 Phys. Rev. Lett. 37 1360

Pillai P K C, Gupta B K and Malti Goel 1981 J. Polym. Sci. Phys. 191461

Sessler G M 1980 Electrets (NY: Springer Verlag)

Talwar I M, Sinha H C and Srivastava A P 1984 Thin Solid Films 113251

Tiwari A R, Saraf K K and Srivastava A P 1982 Thin Solid Films $\mathbf{8 8} 121$

Turnhout J Van 1975 Thermally stimulated discharge of polymer electrets (Amsterdam: Elsevier)

Upadhyay J K, Khare P K, Verma Ashish and Paliwal S K 1998 J. Polym. Mater. 15289

Upadhyay J K, Khare P K and Verma Ashish 1999 Indian J. Phys. A73 183

Verma Deepak and Bhatnagar C S 1976 Indian J. Pure \& Appl. Phys. 1493 